\title{
Impact of the first COVID-19 shutdown on patient volumes and surgical procedures of a Level I trauma center
}

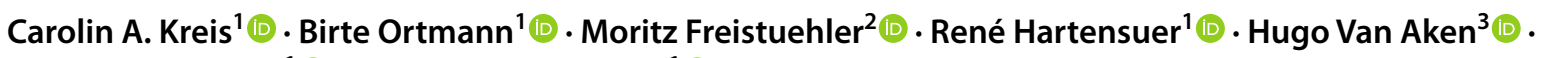 \\ Michael J. Raschke ${ }^{1}$ (i) $\cdot$ Benedikt Schliemann ${ }^{1}$ (1)
}

Received: 18 January 2021 / Accepted: 21 March 2021 / Published online: 21 April 2021

(c) The Author(s) 2021

\begin{abstract}
Purpose In Dec 2019, COVID-19 was first recognized and led to a worldwide pandemic. The German government implemented a shutdown in Mar 2020, affecting outpatient and hospital care. The aim of the present article was to evaluate the impact of the COVID-19 shutdown on patient volumes and surgical procedures of a Level I trauma center in Germany.

Methods All emergency patients were recorded retrospectively during the shutdown and compared to a calendar-matched control period (CTRL). Total emergency patient contacts including trauma mechanisms, injury patterns and operation numbers were recorded including absolute numbers, incidence proportions and risk ratios.

Results During the shutdown period, we observed a decrease of emergency patient cases (417) compared to CTRL (575), a decrease of elective cases (42 vs. 13) and of the total number of operations (397 vs. 325). Incidence proportions of emergency operations increased from 8.2 to $12.2 \%$ (shutdown) and elective surgical cases decreased (11.1 vs. 4.3\%). As we observed a decrease for most trauma mechanisms and injury patterns, we found an increasing incidence proportion for severe open fractures. Household-related injuries were reported with an increasing incidence proportion from 26.8 to $47.5 \%$ (shutdown). We found an increasing tendency of trauma and injuries related to psychological disorders.

Conclusion This analysis shows a decrease of total patient numbers in an emergency department of a Level I trauma center and a decrease of the total number of operations during the shutdown period. Concurrently, we observed an increase of severe open fractures and emergency operations. Furthermore, trauma mechanism changed with less traffic, work and sportsrelated accidents.
\end{abstract}

Keywords SARS-CoV-2 $\cdot$ COVID-19 $\cdot$ Shutdown $\cdot$ Pandemic $\cdot$ Level I trauma center $\cdot$ Emergency operation

\section{Introduction}

In Dec 2019, the Chinese government first reported a new viral disease called COVID-19 caused by a new viral type SARS-CoV-2 followed by a worldwide pandemic with exponential increase of infection rate and serious impact on our healthcare systems, economy, society and social life [1]. To

Michael J. Raschke

michael.raschke@ukmuenster.de

1 Department of Trauma, Hand and Reconstructive Surgery, University Hospital Muenster, Albert-Schweitzer-Campus 1, Building W1, 48149 Muenster, Germany

2 Department of Medical Management and Medical Controlling, University Hospital Muenster, Muenster, Germany

3 University Hospital Muenster, Muenster, Germany monitor the development of viral spread and infection, the reproduction value ( $\mathrm{r}$ value) was recorded by the Robert Koch Institute (RKI), Germany. This value indicates how many people are infected by one infected person and was announced to be $r=2.34$ on Mar 3rd [2].

Due to the pandemic process, the German Government declared a temporary shutdown as necessary to control the infections process, which started on Mar 16th 2020. The major reason and objective for these serious restrictions was on the one hand the control of the infection process and on the other hand, the warranty of sufficient medical care including sufficient intensive care capacities. The temporary shutdown affected all major social institutions: schools, children`s day care institutions, universities, sport clubs and all public leisure institutions, restaurants, bars and nightclubs, theaters and non-essential institutions. Major events were cancelled, and social contacts were restricted 
to a maximum of two households meeting at one time. The healthcare system was obliged to only treat emergencies if possible [3]. On Apr 15th 2020, the German government allowed easing of restrictions with corresponding precautionary measures in compliance with hygiene rules [4].

A nationwide shutdown with all its consequences probably leads to changes in daily life of the population and in economy. Against this background, the question arises whether restrictions, quarantine and isolation led to fundamental changes in daily life and whether there is an impact on trauma numbers, mechanisms and injury patters as well as on operation numbers in a Level I trauma center.

A previous analysis by Haffner et al. showed considerable economical and personnel loss in orthopedic and trauma departments of university hospitals in Germany: the COVID-19 pandemic led to a reduction of operation capacity of $49.4 \%$, a loss of expected income of $29.3 \%$ and a redistribution of specialist staff of $14.7 \%$ [5]. Similar results were found by von Dercks et al. [6]. Their findings demonstrated a reduction of patient cases, a decrease of hospitalized patients and a reduction of occupancy days during the first 7 weeks of the COVID-19 pandemic. Some findings point out the influence on population and a rise of domestic violence and emotional stress, depression, fears, unemployment and reduced income [7, 8]. Data concerning trauma, injury patterns and operation numbers are limited $[9,10]$ but required to understand the consequences of a shutdown in the face of a pandemic.

The aim of our study was to analyze trauma numbers and mechanisms as well as surgical procedures in case of a shutdown due to the occurrence of a pandemic. This study might help to draw consequences for further states of emergencies to coordinate health care systems as the "second pandemic wave" has just "arrived" and an end of the pandemic is not yet in sight. Therefore, we analyzed retrospectively the total and daily numbers of emergency patient contacts including trauma mechanisms and injury patterns as well as operation numbers in a Level I trauma center in Germany during the 35-day period of the COVID-19 shutdown. Findings were compared to a calendar-matched control period (CTRL) in 2019 , to a 15-day pre-shutdown transition and a 15-day postshutdown transition before and after shutdown in Mar/Apr 2020.

\section{Methods}

We analyzed retrospectively all emergency patient records and all operation records of the trauma emergency department of a German Level I trauma center. We evaluated and compared the following time periods: Mar 16th 2019 until Apr 19th 2019 and Mar 16th 2020 until Apr 19th 2020.
Finally, we defined four investigation time periods according to the German Infection Protection Act:

1. Calendar-matched control time (CTRL): Mar 16th 2019-Apr 19th 2019 (35 days)

2. Pre-shutdown time (PREST): Mar 1st 2020-Mar 15th 2020 (15 days)

3. Shutdown time (SHUTDOWN): Mar 16th 2020-Apr 19th 2020 (35 days)

4. Post-shutdown time (POST): Apr 20th 2020-May 4th 2020 (15 days)

All data were taken from the hospital's clinical information system (ORBIS, Dedalus, Health Care, Bonn, Germany). Ethical approval was obtained from the clinical ethics committee (reference number: AZ 2020-397-f-S). Documentation was filtered by epidemiological, clinical and therapeutic parameters.

\section{Data analysis}

Collected data were transferred to IBM SPSS Statistics program for statistical analysis (IBM Corp. Released 2020. IBM SPSS Statistics for Windows, Version 27.0. Armonk, NY: IBM Corp). For statistical analysis, we used descriptive statistical methods with a $95 \%$ confidence interval (CI), which was not adjusted for multiple testing. Therefore, statistical analysis is to be evaluated as explorative with no statistical significance. To capture the total number of ambulant patient cases and operation cases, the cumulative number of cases per day was registered in each of the four investigation time periods. Daily fluctuations were plotted as a calendar time function. A visual shift is to be justified by the year 2020 being a leap year.

Daily cumulative patient cases of the trauma emergency department and numbers of operations of the aforementioned 4 time periods were compared with using incidence rate ratios (IRR). Operations are conducted standardly concerning the Amsterdam Operation Criteria [11]. Daily cumulative cases were determined as an addition of daily treatment divided by the number of days of the corresponding time period. A negative binomial regression analysis defined the IRR and the corresponding 95\% CI. In addition, we analyzed further variables concerning trauma mechanisms and treatments between the CTRL and the shutdown period. The incidence of a variable was defined as numbers of each variable divided by the number of days within respective periods. To compare the CTRL and shutdown period, we calculated risk ratios (RR), quotient from incidence values of the shutdown period and the CTRL and 95\% CI via crosstab and pairwise comparison. Data were plotted as Forest plots by Microsoft Excel (Microsoft Corporation. 
Microsoft Excel for Microsoft 365 MSO, Version 2009. Redmond, Washington: Microsoft Corp).

Death numbers were registered as a cumulation in between $24 \mathrm{~h}$ and during hospitalization. To compare the degree of severity of trauma, the ISS-Score was recorded. Demographic data concerning patients` professions were documented numerically.

According to the German DRG-System, Case mix indexes were also recorded for the CTRL and shutdown period to indicate the average case severity.

\section{Results}

The total number of patient cases in the trauma emergency department was 417 during the shutdown period (35 days), 210 during the pre-shutdown period ( 15 days), 198 during post-shutdown period ( 15 days) and 575 patient cases during CTRL (35 days). This resulted in a lower number of daily cases during the shutdown period $(11.94 \pm 3.404)$ compared to CTRL $(16.43 \pm 4.907)$ with an IRR of 0.73 (shutdown period vs. CTRL, 95\% CI $[0.45 ; 1.18]$ ). The comparison between daily cases during the pre-shutdown period $(14.00 \pm 4.629)$ and CTRL $(16.43 \pm 4.907)$ showed a decrease as well [IRR of 0.85; pre-shutdown vs. CTRL; $95 \%$ CI $(0.46 ; 1.59)]$. A further decrease of daily cases was found when comparing the pre-shutdown $(14.00 \pm 4.629)$ and the shutdown period $(11.94 \pm 3.404)$ with an IRR of
0.85 [pre-shutdown vs. shutdown; 95\% CI $(0.46 ; 1.6)$ ]. Finally, daily cases increased again during the postshutdown period [shutdown period $11.94 \pm 3.404$, postshutdown period $13.13 \pm 3.067$ with an IRR of 1.1 ; postshutdown vs. shutdown; 95\% CI $(0.59 \pm 2.06)$ ] (Table 1 , Fig. 1).

To compare injury patterns, trauma mechanisms, cause of trauma and demographics, RR-values were calculated out of absolute numbers and incidence proportions during the CTRL and the shutdown period. Table 2 illustrates absolute numbers, incidence proportions and RR-values.

The absolute number of trauma-related death during CTRL was 5 and increased to 7 during the shutdown period. 9 polytrauma cases with an ISS of 32.5 were recorded during CTRL and 7 during the shutdown period with an average ISS of 34.1. Overall, traffic-associated accident decreased during the shutdown period. Figure 2 shows the relative risk in detail: the relative risk of car accidents decreased from $3.7 \%$ during CTRL to $2.9 \%$ during the shutdown, of bike accidents from 8.9 to $7.2 \%$ and of pedestrian accidents from 2.6 to $2.2 \%$ during mentioned time periods. The relative risk of scooter accidents (from 2.1 to $2.9 \%$ ) and work injuries (from 12.0 to $14.1 \%$ ) were recorded with a slight increase during the shutdown period compared to CTRL.

The number of work injuries decreased during the shutdown period. We also observed a reduction of the total patient number, which results in a calculated increasing relative risk for work injuries during the shutdown period.

Table 1 Total and daily numbers of total trauma patient cases sorted by defined time periods before, during and after the COVID-19 shutdown

\begin{tabular}{lllll}
\hline & CTRL $(35 \mathrm{~d})$ & PREST $(15 \mathrm{~d})$ & SHUTDOWN $(35 \mathrm{~d})$ & POST $(15 \mathrm{~d})$ \\
\hline Total cases $(n)$ & 575 & 210 & 417 & 198 \\
Daily total cases $( \pm \mathrm{SD})$ & $16.43(4.907)$ & $14.00(4.629)$ & $11.94(3.404)$ & $13.13(3.067)$ \\
IRR $(95 \%$ CI) & SHUTDOWN vs. CTRL & PREST vs. CTRL & SHUTDOWN vs. PREST & POST vs. SHUTDOWN \\
& $0.73(0.45 ; 1.18)$ & $0.85(0.46 ; 1.59)$ & $0.85(0.46 ; 1.6)$ & $1.1(0.59 ; 2.06)$ \\
\hline
\end{tabular}

IRRs are given for indicated time frame comparisons

CTRL control period, PREST pre-shutdown period, SHUTDOWN shutdown, POST post-shutdown period, SD standard deviation, IRR incidence rate ratio; $95 \%$ CI 95\% confidence interval

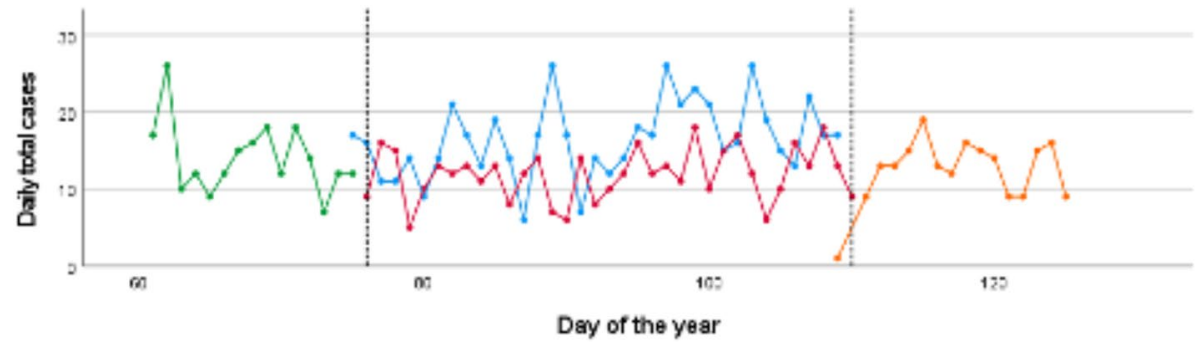

Fig. 1 Development of daily total trauma cases before, during and after the COVID-19 shutdown. The solid lines describe the development in the CTRL-period (blue) in 2019, pre-shutdown (green), shut- down (red) and post-shutdown (orange) period in 2020. Dotted lines indicate the beginning and end of the shutdown period (first line: Mar 16th 2020; second line: Apr 20th 2020) 
Table 2 Gender, trauma environments and cause, non-traumatic orthopedic presentation, trauma mechanism, treatment, admissions/discharges sorted by defined time periods before and during the COVID-19 shutdown

\begin{tabular}{|c|c|c|c|}
\hline & $\begin{array}{l}\text { CTRL }(35 \mathrm{~d}) \\
\text { with total } \mathrm{n} \text { (incidence propor- } \\
\text { tion: } n / 575 \text { in } \%)\end{array}$ & $\begin{array}{l}\text { SHUTDOWN }(35 \mathrm{~d}) \\
\text { with total } \mathrm{n} \text { (incidence propor- } \\
\text { tion: } n / 417 \text { in } \% \text { ) }\end{array}$ & $\begin{array}{l}\text { SHUTDOWN vs. CTRL } \\
(95 \% \mathrm{CI})\end{array}$ \\
\hline All & 575 & 417 & \\
\hline \multicolumn{4}{|l|}{ Gender } \\
\hline Male & $339(59.0)$ & $242(58.0)$ & $0.984(0.885 ; 1.095)$ \\
\hline Female & $236(41.0)$ & $175(42.0)$ & $1.022(0.881 ; 1.187)$ \\
\hline \multicolumn{4}{|l|}{ Substance abuse } \\
\hline Intoxication & $3(0.5)$ & $4(1.0)$ & $1.839(0.414 ; 8.171)$ \\
\hline Alcohol & $25(4.3)$ & $5(1.2)$ & $0.276(0.106 ; 0.714)$ \\
\hline Other & 0 & 0 & - \\
\hline \multicolumn{4}{|l|}{ Serious injuries } \\
\hline Death & $5(0.9)$ & $9(2.2)$ & $2.482(0.838 ; 7.352)$ \\
\hline Polytrauma & $9(1.6)$ & $7(1.7)$ & $1.072(0.403 ; 2.857)$ \\
\hline \multicolumn{4}{|l|}{ Traffic accidents } \\
\hline Car accidents & $21(3.7)$ & $12(2.9)$ & $0.788(0.392 ; 1.583)$ \\
\hline Bike accidents & $51(8.9)$ & $30(7.2)$ & $0.811(0.526 ; 1.251)$ \\
\hline Scooter accidents & $12(2.1)$ & $12(2.9)$ & $1.379(0.626 ; 3.039)$ \\
\hline Pedestrian accidents & $15(2.6)$ & $9(2.2)$ & $0.827(0.366 ; 1.872)$ \\
\hline Public transport accidents & $1(0.2)$ & 0 & - \\
\hline \multicolumn{4}{|l|}{ Workplace accidents } \\
\hline Work injuries & $69(12.0)$ & $59(14.1)$ & $1.179(0.853 ; 1.630)$ \\
\hline Work violence-related injuries & $1(0.2)$ & $1(0.2)$ & $1.379(0.086 ; 21.982)$ \\
\hline \multicolumn{4}{|l|}{ Injuries in private environment } \\
\hline Domestic violence-related injuries & 0 & $1(0.2)$ & \\
\hline Violence-related injuries & $22(3.8)$ & $9(2.2)$ & $0.564(0.262 ; 1.212)$ \\
\hline Robbery-related injuries & 0 & 0 & \\
\hline Party-related injuries & $13(2.3)$ & 0 & \\
\hline Sport injuries & $114(19.8)$ & $41(9.8)$ & $0.496(0.355 ; 0.693)$ \\
\hline Home injuries & $154(26.8)$ & $198(47.5)$ & $1.773(1.498 ; 2.099)$ \\
\hline Suicide attempts & 0 & $4(1.0)$ & \\
\hline Selfharms & $4(0.7)$ & $6(1.4)$ & $2.068(0.587 ; 7.283)$ \\
\hline Psychological disorders & $2(0.3)$ & $2(0.5)$ & $1.379(0.195 ; 9.749)$ \\
\hline \multicolumn{4}{|l|}{ Non-traumatic orthopedic presentations } \\
\hline General diseases & $9(1.6)$ & $10(2.4)$ & $1.532(0.628 ; 3.737)$ \\
\hline Check up & $42(7.3)$ & $13(3.1)$ & $0.427(0.232 ; 0.785)$ \\
\hline \multicolumn{4}{|l|}{ Trauma mechanisms } \\
\hline Blunt & $407(70.9)$ & $303(72.7)$ & $1.025(0.947 ; 1.109)$ \\
\hline Cut & $39(6.8)$ & $57(13.7)$ & $2.015(1.368 ; 2.969)$ \\
\hline Penetration & $24(4.2)$ & $28(6.7)$ & $1.609(0.946 ; 2.734)$ \\
\hline Shot & $1(0.2)$ & 0 & \\
\hline Burn & $4(0.7)$ & $11(2.6)$ & $3.792(1.216 ; 11.826)$ \\
\hline Bite & $4(0.7)$ & $3(0.7)$ & $1.034(0.233 ; 4.596)$ \\
\hline Fall $<3 \mathrm{~m}$ & $221(38.4)$ & $172(41.2)$ & $1.073(0.920 ; 1.252)$ \\
\hline Fall $>3 \mathrm{~m}$ & $10(1.7)$ & $7(1.7)$ & $0.965(0.370 ; 2.515)$ \\
\hline \multicolumn{4}{|l|}{ Therapy } \\
\hline Emergency surgery & $47(8.2)$ & $51(12.2)$ & $1.496(1.028 ; 2.179)$ \\
\hline Semi-elective surgery & $64(11.1)$ & $18(4.3)$ & $0.388(0.233 ; 0.644)$ \\
\hline Conservative treatment & $368(64.0)$ & $344(82.5)$ & $1.289(1.195 ; 1.390)$ \\
\hline
\end{tabular}


Table 2 (continued)

\begin{tabular}{|c|c|c|c|}
\hline & $\begin{array}{l}\text { CTRL ( } 35 \mathrm{~d}) \\
\text { with total } \mathrm{n} \text { (incidence propor- } \\
\text { tion: } n / 575 \text { in } \% \text { ) }\end{array}$ & $\begin{array}{l}\text { SHUTDOWN }(35 \mathrm{~d}) \\
\text { with total } \mathrm{n} \text { (incidence propor- } \\
\text { tion: } n / 417 \text { in } \% \text { ) }\end{array}$ & $\begin{array}{l}\text { SHUTDOWN vs. CTRL } \\
(95 \% \mathrm{CI})\end{array}$ \\
\hline \multicolumn{4}{|l|}{ Admissions/discharges } \\
\hline Ambulantory care & $284(49.4)$ & $290(69.5)$ & $1.408(1.269 ; 1.563)$ \\
\hline Self discharged & $17(3.0)$ & $18(4.3)$ & $1.460(0.762 ; 2.799)$ \\
\hline Stationary admission & $262(45.6)$ & $100(24.0)$ & $0.526(0.434 ; 0.638)$ \\
\hline Discharged $24 \mathrm{~h}$ & $33(5.7)$ & $27(6.5)$ & $1.128(0.689 ; 1.847)$ \\
\hline Discharged $\leq 5 \mathrm{~d}$ & $145(25.2)$ & $31(7.4)$ & $0.295(0.204 ; 0.425)$ \\
\hline Discharged $\leq 7 \mathrm{~d}$ & $23(4.0)$ & $10(2.4)$ & $0.600(0.288 ; 1.246)$ \\
\hline Discharged $\leq 1$ month & $55(9.6)$ & $30(7.2)$ & $0.752(0.491 ; 1.152)$ \\
\hline Discharged $\geq 1$ month & $7(1.2)$ & $2(0.5)$ & $0.394(0.082 ; 1.887)$ \\
\hline Send to other facility & $17(3.0)$ & $20(4.8)$ & $1.622(0.860 ; 3.059)$ \\
\hline
\end{tabular}

Total numbers and incidence proportions are given for defined time periods in first two columns and RRs show the comparison between the SHUTDOWN and CTRL, relative to trauma case numbers, in the third column. All RRs related to a CI not including 1 are highlighted in bold CTRL control, SHUTDOWN shutdown, RR risk ratio, $95 \%$ confidence interval

Fig. 2 Forest plot of the relative risk for traffic and work accidents during the shutdown period: the relative risk of car, bike and pedestrian accidents decreased. The relative risk of scooter and work injuries were recorded with a slight increase during the shutdown period compared to CTRL

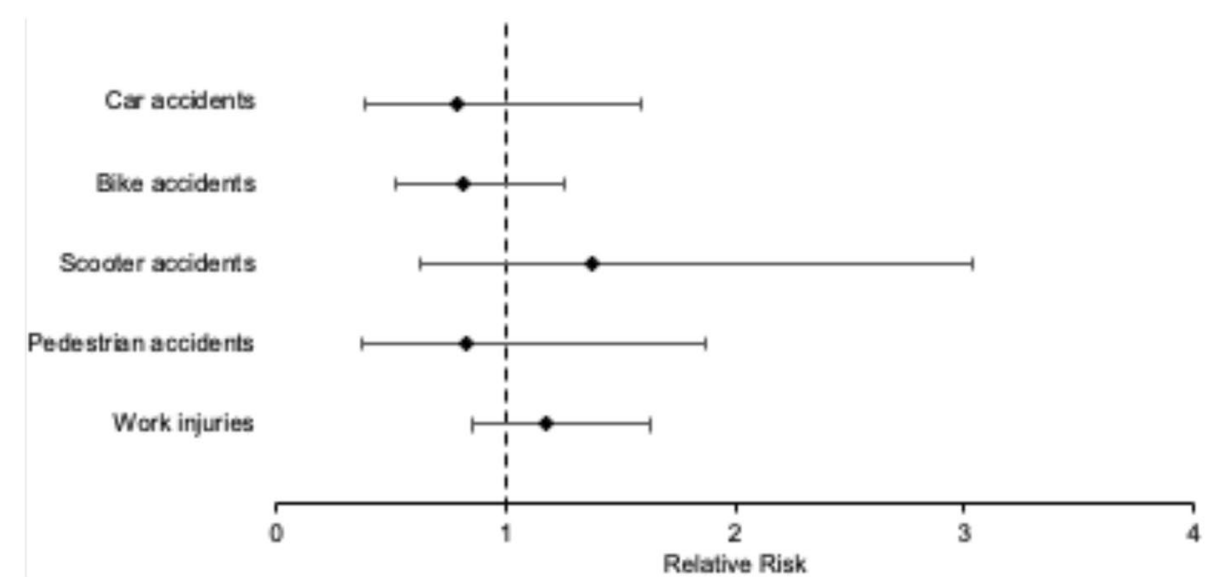

Table 3 Absolut numbers of type of employment sorted by defined time periods before and during the COVID-19 shutdown

\begin{tabular}{lrc}
\hline & CTRL (35d) & $\begin{array}{l}\text { SHUT- } \\
\text { DOWN } \\
(35 d)\end{array}$ \\
\hline All & 575 & 417 \\
Office & 7 & 1 \\
Manual & 43 & 15 \\
Public & 8 & 0 \\
Medical & 19 & 29 \\
Student & 20 & 0 \\
\hline
\end{tabular}

Tables 2, 3 give detailed information concerning demographics and working background. Professional activities were documented with absolute numbers. Noticeable is a decrease in employment (98 during CTRL and 45 during shutdown), in office work, manual workman and students in contrast to an increase of injured medical staff (19 during CTRL and 29 during shutdown).

The absolute number of household accidents increased from 154 during CTRL to 198 during the shutdown period with a corresponding increase of incidence proportion from 26.8 to $47.5 \%$, which results in a RR-value of 1.773 [CTRL vs. shutdown period; 95\% CI $(1.498 ; 2.099)]$. While the absolute number of sport injuries decreased from 114 (incidence proportion: 19.8\%) during CTRL to 41 (incidence proportion: $9.8 \%$ ) during the shutdown period with a decreasing incidence proportion and a resulting RR-value of 0.496 [CTRL vs. shutdown; 95\% CI (0.355; 0.693)]. Four cases of suicide attempts were recorded (incidence proportion: $1.0 \%$ ) during the shutdown period and no case during CTRL. Absolute numbers of self-harm increased slightly from 4 during CTRL to 6 during the shutdown period, resulting in incidence proportions of 0.7 an $1.4 \%$. Comparable tendencies could be found concerning psychological 


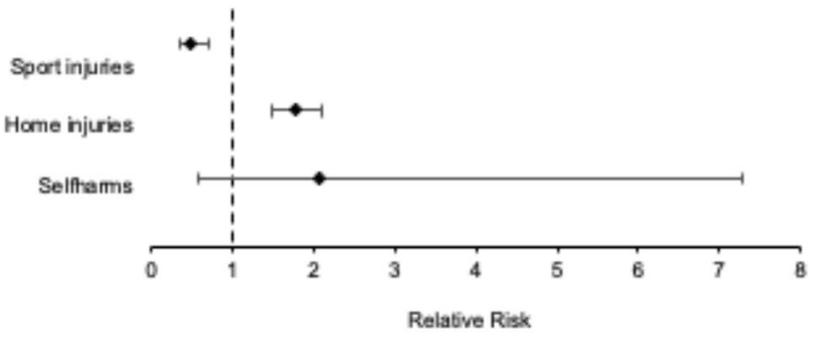

Fig. 3 Forest plot of the relative risk for home, sport, psychological attempted injuries during the shutdown period with an increase concerning home and psychological attempted injuries and a decrease concerning sport injuries

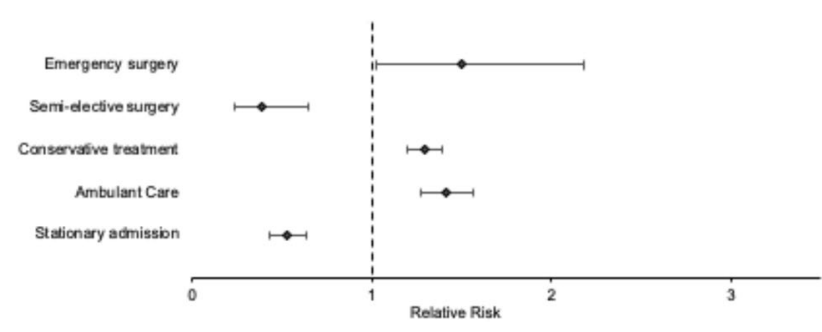

Fig. 4 Forest plot of the relative risk of different treatment modalities during the shutdown period with an increase of emergency surgery and a decrease of elective surgery and hospitalization. During the shutdown period, the relative risk of conservative treatment and ambulant care increased

disorders with increasing incidence proportions from 0.3 (CTRL) to $0.5 \%$ (shutdown) (Fig. 3).

Figure 4 shows the relative risk for different treatment modalities. Absolute numbers of emergency surgery increased during the shutdown period with an increasing incidence proportion from 8.2 to $12.2 \%$ resulting in an RR of 1.496 [CTRL vs. shutdown; 95\% CI (1.028; 2.179)]. Emergency surgery is defined as immediate surgery after admission and primary diagnosis. According to the requirements of the German government, elective surgery was reduced with incidence proportions of $11.1 \%$ during CTRL to $4.3 \%$ during shutdown period [RR of 0.388; CTRL vs. shutdown; 95\% CI $(0.233$; 0.644)]. Accordingly, fewer patients were hospitalized (262 during CTRL vs. 100 during the shutdown) (Fig. 4).

Overall, absolute number of fractures decreased from 227 during CTRL to 161 during shutdown with a corresponding incidence proportion of $39.5-38.6 \%$. Table 4 shows the distribution of fracture localizations. A noticeable and statistically significant increase of open fractures was recorded during shutdown period with an incidence proportion of $2.6 \%$ (0.9\% during CTRL) and a RR-value of 3.034 [CTRL vs. shutdown; 95\% CI $(1.062 ; 8.665)]$. Accordingly, the incidence proportion of open soft tissue injuries increased from 27.8 (CTRL) to $43.2 \%$ during shutdown period with a RR-value of 1.551 [CTRL vs. shutdown; 95\% CI (1.307; 1.842)] (Table 4).

397 surgeries were performed during CTRL compared to 325 during the shutdown period. The amount of daily operation decreased from 11.68 operations/day during CTRL to 9.29 operations/day during the shutdown period with an IRR of 0.8 [shutdown vs. CTRL; 95\% CI $(0.49 ; 1.30)$ ] (Table 5 , Fig. 5).

According to requirements given by the German government, we found more high urgency surgeries compared to CTRL. A significant decrease of elective surgery was reported with $33(10.2 \%)$ cases during the shutdown period compared to $261(65.7 \%)$ cases during CTRL, which results in a RR-value of 0.154 [CTRL vs. shutdown; $95 \%$ CI $(0.111$; $0.215)]$. The classification to an elective type of surgery was related to the indication. Due to certain reasons, such as decompensation of chronic disorders these surgeries were performed. Furthermore, an increase of all urgent operations according to the Amsterdam Criteria was found (Fig. 6, Table 6).

In addition, we observed a reduction of total operation time of $18 \%$ during the shutdown period compared to CTRL. The Case Mix Index (CMI) as a measure for case severity, calculated by the hospital's Diagnosis Related Group (DRG)-System, resulted in an increase of 0.32 points with a $\mathrm{CMI}=2.32$ during the shutdown period and $\mathrm{CMI}=2.00$ during CTRL.

\section{Discussion}

Our study evaluates the impact of the COVID-19 shutdown in Germany on patient numbers, injury patterns and operation numbers on a German Level I trauma center. Overall, we observed a decrease of patient numbers in our emergency department: compared to a calendar-matched time period in 2019 patient, cases declined by about 30\% (absolute numbers) during the shutdown period and by about $15 \%$ during the pre-shutdown period. In temporal connection, an increase of absolute numbers of patient cases of $10 \%$ was observed comparing the shutdown versus the post-shutdown period. A similar tendency was reported in an analysis by Christey et al. [12]. They documented a decrease of absolute admission numbers due to injury of $43 \%$ in a trauma center in New Zealand. In accordance, an American group analyzed average daily patient cases in a face and hand surgery department of a Level I trauma center in Chicago, Illinois 3 weeks before and 3 weeks after the "stay-at-home prescription". They found a decrease of average daily cases from 4.2 to 2.9 [13].

We also evaluated the impact of the COVID-19 shutdown on operation numbers. Compared to 2019, we found the absolute numbers to be declined by about $5 \%$ during the 
Table 4 Diagnosis of the trauma cases (fracture, soft tissue injury, brain injury) sorted by defined time periods before and during the COVID-19 shutdown

\begin{tabular}{|c|c|c|c|}
\hline & $\begin{array}{l}\text { CTRL }(35 \mathrm{~d}) \\
\text { with total } \mathrm{n} \text { (incidence propor- } \\
\text { tion: } n / 575 \text { in } \%)\end{array}$ & $\begin{array}{l}\text { SHUTDOWN }(35 \mathrm{~d}) \\
\text { with total } \mathrm{n} \text { (incidence propor- } \\
\text { tion: } n / 417 \text { in } \%)\end{array}$ & $\begin{array}{l}\text { SHUTDOWN vs. CTRL RR } \\
(95 \% \mathrm{CI})\end{array}$ \\
\hline All & 575 & 417 & \\
\hline \multicolumn{4}{|l|}{ Fracture } \\
\hline All fractures & $227(39.5)$ & $161(38.6)$ & \\
\hline Facial fracture & $29(5.0)$ & 19 (4.6) & $0.903(0.514 ; 1.589)$ \\
\hline Skull fracture & $11(1.9)$ & $3(0.7)$ & $0.376(0.106 ; 1.340)$ \\
\hline Clavicle fracture & $14(2.4)$ & $11(2.6)$ & $1.083(0.497 ; 2.362)$ \\
\hline Humerus fracture & $9(1.6)$ & $8(1.9)$ & $1.226(0.477 ; 3.150)$ \\
\hline Olecranon fracture & $3(0.5)$ & $2(0.5)$ & $0.919(0.154 ; 5.477)$ \\
\hline Radius/ulnar fracture & $21(3.7)$ & $21(5.0)$ & $1.379(0.763 ; 2.491)$ \\
\hline Hand fracture & $32(5.6)$ & $20(4.8)$ & $0.862(0.500 ; 1.485)$ \\
\hline Thorax fracture & $20(3.5)$ & $8(1.9)$ & $0.552(0.245 ; 1.240)$ \\
\hline Occipital/cervical spine fracture & $13(2.3)$ & $6(1.4)$ & $0.636(0.244 ; 1.661)$ \\
\hline Cervical spine fracture & $5(0.9)$ & $3(0.7)$ & $0.827(0.199 ; 3.443)$ \\
\hline Thoracic spine fracture & 0 & 0 & \\
\hline Lumbar spine fracture & $7(1.2)$ & $6(1.4)$ & $1.182(0.400 ; 3.491)$ \\
\hline Sacral spine fracture & $3(0.5)$ & $4(1.0)$ & $1.839(0.414 ; 8.171)$ \\
\hline Pelvis fracture & $9(1.6)$ & $12(2.9)$ & $1.839(0.782 ; 4.323)$ \\
\hline Femoral fracture & $11(1.9)$ & $12(2.9)$ & $1.504(0.670 ; 3.376)$ \\
\hline Tibia/fibula fracture & $14(2.4)$ & $14(3.4)$ & $1.379(0.665 ; 2.861)$ \\
\hline Patella fracture & $6(1.0)$ & $1(0.2)$ & $0.230(0.028 ; 1.902)$ \\
\hline Foot fracture & $20(3.5)$ & $11(2.6)$ & $0.758(0.367 ; 1.566)$ \\
\hline Open fracture & $5(0.9)$ & $11(2.6)$ & $3.034(1.062 ; 8.665)$ \\
\hline \multicolumn{4}{|l|}{ Soft tissue injury } \\
\hline Closed soft tissue injury & $381(66.4)$ & $246(59.0)$ & $0.889(0.805 ; 0.981)$ \\
\hline Open soft tissue injury & $160(27.8)$ & $180(43.2)$ & $1.551(1.307 ; 1.842)$ \\
\hline Bleeding soft tissue injury & $131(22.8)$ & $130(31.2)$ & $1.368(1.112 ; 1.684)$ \\
\hline \multicolumn{4}{|l|}{ Brain injury } \\
\hline SHT & $68(11.8)$ & $43(10.3)$ & $0.872(0.608 ; 1.250)$ \\
\hline EDB & $1(0.2)$ & $1(0.2)$ & $1.379(0.086 ; 21.982)$ \\
\hline SDB & $8(1.4)$ & $4(1.0)$ & $0.689(0.209 ; 2.274)$ \\
\hline SAB & $3(0.5)$ & 0 & \\
\hline ICB & $2(0.3)$ & $2(0.5)$ & $1.379(0.195 ; 9.749)$ \\
\hline \multicolumn{4}{|l|}{ Trauma } \\
\hline Thoracic trauma & $4(0.7)$ & $6(1.4)$ & $2.068(0.587 ; 7.283)$ \\
\hline Pneumothorax & $9(1.6)$ & $2(0.5)$ & $0.306(0.067 ; 1.411)$ \\
\hline Abdomentrauma & $1(0.2)$ & $1(0.2)$ & $1.379(0.086 ; 21.982)$ \\
\hline
\end{tabular}

Total numbers and incidence proportions are given for defined time periods in first two columns and RRs show the comparison between the SHUTDOWN and CTRL, relative to trauma case numbers, in the third column. All RRs related to a CI not including 1 are highlighted in bold

CTRL control, SHUTDOWN shutdown, $R R$ risk ratio, $95 \%$ confidence interval

pre-shutdown period and of about $20 \%$ during the shutdown period. The post-shutdown period showed an increase of absolute operation numbers of about $10 \%$. A report of the Imperial College Healthcare NHS Trust and North West London Major Trauma Centre (Level I trauma center, London, UK) reveals a decrease of $1 / 3$ of operation numbers in comparable time periods due to cancellation of semi-elective and elective surgery and underlines our findings [10]. A retrospective study from Italy goes in accordance with those data. This group showed a reduction of emergency surgery of $41.3 \%$ at the peak of pandemic shutdown (with comparable time periods) in a department of general surgery in the University Hospital of Ferrara, Italy, which is located in the Emilia Romagna—a region which was nearly most affected 
Table 5 Total and daily numbers of total OP patient cases sorted by defined time periods before, during and after the COVID-19 shutdown

\begin{tabular}{lllll}
\hline & CTRL $(35 \mathrm{~d})$ & PREST $(15 \mathrm{~d})$ & SHUTDWON $(35 \mathrm{~d})$ & POST $(15 \mathrm{~d})$ \\
\hline Totale cases $(n)$ & 397 & 165 & 325 & 141 \\
Daily total cases $( \pm$ SD) & $11.68(6.094)$ & $11.00(6.256)$ & $9.29(4.719)$ & $10.07(5.121)$ \\
IRR $(95 \%$ CI) & SHUTDOWN vs. CTRL & PREST vs. CTRL & SHUTDOWN vs. PREST & POST vs. SHUTDOWN \\
& $0.80(0.49 ; 1.30)$ & $0.94(0.5 ; 1.78)$ & $0.84(0.45 ; 1.59)$ & $1.08(0.57 ; 2.08)$ \\
\hline
\end{tabular}

IRRs are given for indicated time frame comparisons

CTRL control period, PREST pre-shutdown period, SHUTDOWN shutdown, POST post-shutdown period, SD standard deviation, IRR incidence rate ratio, $95 \%$ CI $95 \%$ confidence interval

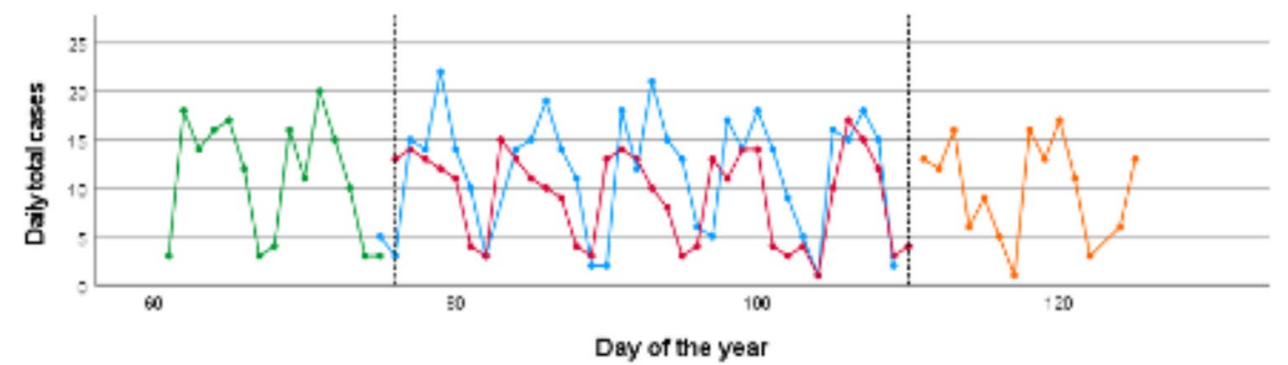

Fig. 5 Development of daily total OP cases before, during and after the COVID-19 shutdown. The solid lines describe the development in the CTRL-period (blue) in 2019, pre-shutdown (green), shutdown

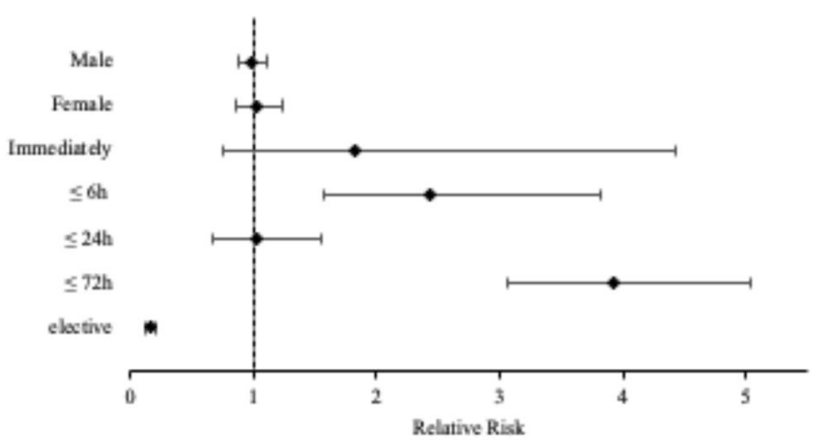

Fig. 6 Forest plot of the relative risk of surgery during the shutdown period. During the shutdown period, an increase of high urgency surgeries and a decrease of elective surgery were recorded

by the pandemic in Europe [14]. Both studies mentioned above describe a reduction of operation numbers in accordance to severity of local infection numbers and to country specific restrictions.

Concerning the operation numbers in detail, we can indicate a reduction of elective surgery of $85 \%$ during shutdown period compared to 2019 and a 2.5 -fold increase of emergency surgery during the shutdown period, which is in contrast with the aforementioned findings from Italy. The significant increase of emergency surgeries might be explained through the local structure of regional trauma (red) and post-shutdown (orange) period in 2020. Dotted lines indicate the beginning and end of the shutdown period (first line: Mar 16th 2020, second line: Apr 20th 2020)

centers, where the shutdown and quarantine of medical staff affected the availability of these units.

Analysis of demographic data concerning professions shows a decrease of injuries in connection with office work, manual work and being a student. This can be explained by the governmental restrictions. In contrast, we found an increase of patient cases of medical staff. This might be explained by high medical workload and a need of necessary work protection. Haffner et al. already pointed out the need of appropriate supply of university hospitals in Germany [5]. Concerning the distribution of age, we observed a decrease of patient cases with the age 19-29 years, probably due to restrictions and quarantine.

With regard to trauma mechanisms, we found a clear reduction of alcohol intoxication/abuse of about $70 \%$ during shutdown. This was unexpected and contradict with findings from China. Evaluation of SARS-epidemic in 2003 shows and predicts an increase of alcohol consumption during epidemic events [15]. As expected, and in connection with quarantine and stay-at-home-rules, household accidents ascend up to $70 \%$ during the shutdown period in contrast to sport injuries, which decreased by about $50 \%$. Our findings go in accordance with previous data from Park et al. This group found a decrease of comparable trauma mechanism of about $89 \%$ [10]. 
Table 6 Gender and priority of the surgeries sorted by defined time periods before and during the COVID-19 shutdown

\begin{tabular}{|c|c|c|c|}
\hline & $\begin{array}{l}\text { CTRL (35d) } \\
\text { with total } \mathrm{n} \text { (incidence } \\
\text { proportion: } n / 397 \text { in \%) }\end{array}$ & $\begin{array}{l}\text { SHUTDOWN (35d) } \\
\text { with total } \mathrm{n} \text { (incidence } \\
\text { proportion: } n / 325 \text { in } \% \text { ) }\end{array}$ & $\begin{array}{l}\text { SHUTDOWN vs. CTRL RR } \\
(95 \% \mathrm{CI})\end{array}$ \\
\hline All & 397 & 325 & \\
\hline \multicolumn{4}{|l|}{ Gender } \\
\hline Male & $244(61.5)$ & $197(60.6)$ & $0.986(0.877 ; 1.109)$ \\
\hline Female & $153(38.5)$ & $128(39.4)$ & $1.022(0.851 ; 1.228)$ \\
\hline \multicolumn{4}{|l|}{ Serious injuries } \\
\hline $\begin{array}{l}\text { Death during } \\
\text { hospital stay }\end{array}$ & $6(1.5) / 0$ & $6(1.8) / 2(0.6)$ & \\
\hline Polytrauma & $3(0.8)$ & $9(2.8)$ & \\
\hline \multicolumn{4}{|l|}{ Surgery } \\
\hline Immediate & $8(2.0)$ & $12(3.7)$ & $1.832(0.758 ; 4.429)$ \\
\hline$\leq 6 \mathrm{~h}$ & $26(6.5)$ & $52(16.0)$ & $2.443(1.562 ; 3.821)$ \\
\hline$\leq 24 \mathrm{~h}$ & $42(10.6)$ & $35(10.8)$ & $1.018(0.666 ; 1.555)$ \\
\hline$\leq 72 \mathrm{~h}$ & $60(15.1)$ & $193(59.4)$ & $3.929(3.061 ; 5.045)$ \\
\hline Elective & $261(65.7)$ & $33(10.2)$ & $0.154(0.111 ; 0.215)$ \\
\hline
\end{tabular}

Total numbers and incidence proportions are given for defined time periods in first two columns and RRs show the comparison between the SHUTDOWN and CTRL, relative to OP case numbers, in the third column

All RRs related to a CI not including 1 are highlighted in bold

CTRL control, SHUTDOWN shutdown, $R R$ risk ratio, $95 \%$ confidence interval
Our emergency department noted just one case of domestic violence during shutdown period with an uncertain number of unreported cases. This is unexpected as several studies alert to rising numbers of domestic violence in accordance to mental stress, social isolation, narrowness and due to fears $[16,17]$. Furthermore, we documented four cases of suicide attempts during shutdown period. This was expected and goes in accordance with findings of Sher et al. This group underlines a rising tendency of suicide attempts during and after COVID-19 pandemic as a result of psychological (subsequent) damage. Quarantine, isolation and pandemic afflict general public and have a tendency to exacerbate exciting psychological diseases [18]. Here, prevention is necessary in cases of social isolation for whatever reason. Colleagues from Germany state the same tendencies and the recommendation of prevention [19]. In addition, our results show a slight decrease of traffic accidents, which can be explained by governmental restrictions and a high percentage of home office work.

Furthermore, we looked at injury patterns in detail. During the shutdown period, we observed a reduction of total number of fractures of about $30 \%$ in comparison to the defined control period in 2019. Our data go in accordance with reports of Turkey and the USA. Study groups could also show a reduction of fracture incidence of about $30 \%$ $[20,21]$. Furthermore, these findings are in accordance with the results of two studies from Italy that also documented a decrease of the total amount of fractures during COVID-19 shutdown $[22,23]$. We found no statistical relevant results concerning the location of the fractures. However, the number of open fractures was three times higher during shutdown period as it was during control time period in 2019.

In accordance to the restrictions of the German government, we recorded an increase of ambulant cases of $40 \%$ during shutdown period compared to 2019 and a decrease of hospitalization of $50 \%$ during shutdown period, which reflects the reduction of elective and semi-elective surgery.

Limitations of our study are the retrospective and monocentric character with a limit of case numbers and potential confounding factors. Further analysis of date and comparison to further Level I trauma centers are necessary. In addition, surrounding hospitals focused on COVID-19-patients and transferred others. A further limitation might be the choice of our control time period in 2019. The question remains, if this chosen time period is representative.

To conclude our findings, we saw a decrease of total patient numbers in an emergency department of a Level I trauma center and a decrease of total number of operations during shutdown period. Concurrently, we observed an increase of severe open fractures and emergency/urgent operations, which goes in accordance with the higher CMIpoints and only a slight decrease of operation time (cut to suture). Furthermore, trauma mechanism changed with less traffic, sport and work accidents. Our findings seem to be related to restrictions of the German government and their aim to control the infection process and to assure medical care including intensive care capacities during shutdown. Our findings are important for resource planning during 
potential future shutdowns and will hopefully help for further planning concerning distribution of support and medical treatment.

Author's contributions All the authors whose names appear on the submission: (1) made substantial contributions to the conception or design of the work; or the acquisition, analysis, or interpretation of data; or the creation of new software used in the work; (2) drafted the work or revised it critically for important intellectual content; (3) approved the version to be published; and (4) agree to be accountable for all aspects of the work in ensuring that questions related to the accuracy or integrity of any part of the work are appropriately investigated and resolved.

Funding Open Access funding enabled and organized by Projekt DEAL. No funding was received for conducting this study by any author.

Data availability The manuscript, including related data, figures and tables has not been previously published and is not under consideration elsewhere.

Code availability Software applications were used properly.

\section{Declarations}

Conflict of interest The authors have no conflicts of interest to declare that are relevant to the content of this article.

Ethical approval Approval was obtained from the ethics committee of the University Muenster, Germany, and is attached with file number: 2020-397-f-S

Open Access This article is licensed under a Creative Commons Attribution 4.0 International License, which permits use, sharing, adaptation, distribution and reproduction in any medium or format, as long as you give appropriate credit to the original author(s) and the source, provide a link to the Creative Commons licence, and indicate if changes were made. The images or other third party material in this article are included in the article's Creative Commons licence, unless indicated otherwise in a credit line to the material. If material is not included in the article's Creative Commons licence and your intended use is not permitted by statutory regulation or exceeds the permitted use, you will need to obtain permission directly from the copyright holder. To view a copy of this licence, visit http://creativecommons.org/licenses/by/4.0/.

\section{References}

1. WHO-Regionalbüro für Europa. Ausbruch der CoronavirusKrankheit (COVID-19): Pandemie der Coronavirus-Krankheit (COVID-19); 2020 [cited 2020 Sep 14]. Available from: URL: https://www.euro.who.int/de/health-topics/health-emergencies/ coronavirus-covid-19.

2. Robert Koch Institut. Nowcasting und R-Schätzung: Schätzung der aktuellen Entwicklung der SARS-CoV-2-Epidemie in Deutschland; 2020 [cited 2020 Jul 29]. Available from: URL: https://www.rki.de/DE/Content/InfAZ/N/Neuartiges_Coronavirus/Projekte_RKI/Nowcasting.html.

3. Die Bundesregierung. Besprechung der Bundeskanzlerin mit den Regierungschefinnen und Regierungschefs der Länder am 12. März 2020; 2020 [cited 2020 Sep 14]. Available from: URL: https://www.bundesregierung.de/breg-de/themen/coronavirus/ beschluss-zu-corona-1730292.

4. Bundesregierung der Bundesrepublik Deutschland. Telefonschaltkonferenz der Bundeskanzlerin mit den Regierungschefinnen und Regierungschefs der Länder am 15. April 2020; 2020 [cited 2020 Sep 22]. Available from: URL: https://www.bundesregierung.de/ breg-de/aktuelles/bund-laender-beschluss-1744224.

5. Haffer H, Schömig F, Rickert M, Randau T, Raschke M, Wirtz $\mathrm{D}$, et al. Impact of the COVID-19 pandemic on orthopaedic and trauma surgery in University Hospitals in Germany: results of a Nationwide Survey. J Bone Joint Surg Am. 2020;102(14):e78.

6. von Dercks N, Seehofer D, Steinert M, Krämer S, Branzan D, Dietrich A, et al. Wie stark trifft die Corona-Pandemie die chirurgische Klinik eines universitären Maximalversorgers? Der Chirurg. 2020;91(9):755-61.

7. Brooks SK, Webster RK, Smith LE, Woodland L, Wessely S, Greenberg N, et al. The psychological impact of quarantine and how to reduce it: rapid review of the evidence. Lancet. 2020;395(10227):912-20.

8. Moreira DN, Pinto da Costa M. The impact of the Covid-19 pandemic in the precipitation of intimate partner violence. Int J Law Psychiatry. 2020;71:101606.

9. Nuñez JH, Sallent A, Lakhani K, Guerra-Farfan E, Vidal N, Ekhtiari S, et al. Impact of the COVID-19 pandemic on an emergency traumatology service: experience at a tertiary trauma centre in Spain. Injury. 2020;51(7):1414-8.

10. Park C, Sugand K, Nathwani D, Bhattacharya R, Sarraf KM. Impact of the COVID-19 pandemic on orthopedic trauma workload in a London level 1 trauma center: the "golden month." Acta Orthop. 2020;91(5):556-551.

11. Academisch Medisch Centrum - Universiteit van Amsterdam (ed) OK-Reglement 2013: Operatiecentrum (klinische OK en dagcentrum), divisie H, AMC; 2013. p. 40.

12. Christey G, Amey J, Campbell A, Smith A. Variation in volumes and characteristics of trauma patients admitted to a level one trauma centre during national level 4 lockdown for COVID-19 in New Zealand. N Z Med J. 2020;133(1513):81-8.

13. Hassan K, Prescher H, Wang F, Chang DW, Reid RR. Evaluating the effects of COVID-19 on plastic surgery emergencies: protocols and analysis from a Level I trauma center. Ann Plast Surg. 2020;85(Suppl 2):S161-5.

14. D’Urbano F, Fabbri N, Koleva Radica M, Rossin E, Carcoforo P. Emergency surgery in COVID-19 outbreak: has anything changed? Single center experience. World J Clin Cases. 2020;8(17):3691-6.

15. Wu P, Liu X, Fang Y, Fan B, Fuller CJ, Guan Z, et al. Alcohol abuse/dependence symptoms among hospital employees exposed to a SARS outbreak. Alcohol Alcohol. 2008;43(6):706-12.

16. Mazza M, Marano G, Lai C, Janiri L, Sani G. Danger in danger: interpersonal violence during COVID-19 quarantine. Psychiatry Res. 2020;289:113046.

17. Kothari CL, Rhodes KV. Missed opportunities: emergency department visits by police-identified victims of intimate partner violence. Am Coll Emerg Phys. 2020;47(2):190-9.

18. Sher $L$. The impact of the COVID-19 pandemic on suicide rates QJM. 2020;113(10):707-12.

19. Zielasek J, Gouzoulis-Mayfrank E. COVID-19-Pandemie-Psychische Störungen werden zunehmen. Deutsches Aerzteblatt, Jg. 117, Heft 21, 22. Mai 2020

20. Turgut A, Arlı H, Altundağ Ü, Hancıoğlu S, Egeli E, Kalenderer Ö. Effect of COVID-19 pandemic on the fracture demographics: data from a tertiary care hospital in Turkey. Acta Orthop Traumatol Turc. 2020;54(4):355-63.

21. Bram JT, Johnson MA, Magee LC, Mehta NN, Fazal FZ, Baldwin $\mathrm{KD}$, et al. Where have all the fractures gone? The epidemiology 
of pediatric fractures during the COVID-19 pandemic. J Pediatr Orthop. 2020;40(8):373-9.

22. Gumina S, Proietti R, Polizzotti G, Carbone S, Candela V. The impact of COVID-19 on shoulder and elbow trauma: an Italian survey. J Shoulder Elbow Surg. 2020;29(9):1737-42.
23. Maniscalco P, Poggiali E, Quattrini F, Ciatti C, Magnacavallo A, Vercelli A, et al. Proximal femur fractures in COVID-19 emergency: the experience of two orthopedics and traumatology Departments in the first eight weeks of the Italian epidemic. Acta Biomed. 2020;91(2):89-96. 